\title{
Differentiated and Career Directed Education - A Means to Improve the Teaching / Learning Effectiveness in South African Schools
}

\author{
Dr FA Naude \\ School of Teacher Education, Faculty of Humanities, Central University of Technology \\ Email: fnaude@cut.ac.za
}

\section{Doi:10.5901/mjss.2014.v5n27p506}

\begin{abstract}
The discontinuation of higher grade (HG) and standard grade (SG) subjects resulted in the abolishment of HG and SG subject choice opportunities for learners. This effected the subject combination possibilities of learners. One of the effects was the introduction of Mathematical Literacy for learners, not equipped enough to cope with Mathematics as such. The same phenomena was evident in other subjects such as Accounting where learners opted for "easier" subjects such as "learning subjects" because of problems coping with the subject in its "original format". This can be seen as a contributing factor leading to "inferior" subject choices and limited career opportunities. The argumentation of this paper should firstly be seen as an attempt to introduce a system of differentiated teaching which can alleviate stress among learners, resulting from unmanageable academic pressure, and which can improve social adjustment and ensure optimal personal development of learners. The value of career directing information and career directed education as motivational factors in teaching/learning should not be underestimated. From findings in this field, and own provisional research and experience, it became clear that not enough is done to prepare learners for life after school. Effective school guidance and counseling programmes in schools facilitate students' development in educational, personal, social and career domains. Differentiated and career directed education should therefore be further researched as a possible way to improve the teaching / learning process.
\end{abstract}

Keywords: Life Orientation (LO); Mathematical Literacy; Differentiated teaching; Career directed teaching.

\section{Introduction}

People in both the academic and industrial sector often voice concerns about an expected shortage of artisans in the near future and the seemingly inability of the schooling system to provide both the labour market and training institutions with well-prepared clients - workers and potential or prospective students. Mhlanga (2012) states that South Africa is getting obsessed to improve the matric pass rate while little or no attention is given to career guidance. This causes the majority of matriculants to flock to universities while further education and training colleges are far from reaching the government's target to enroll one million learners by 2015. It is therefore evident that learners seem to be unable to make informed, wise and calculated decisions in terms of further studies or training and career choices in general due to inadequate guidance and information. Career guidance and simultaneously proper guidance in terms of subject choice, could contribute substantially in giving learners confidence to decide where they want to be in future in terms of careers.

Proper career guidance and the selection of subjects in line with a candidate's future plans and abilities, interests, etc. can contribute to at least making the situation manageable for learners and institutions of higher learning (Mhlanga, 2012) and also serve as a motivating factor to achieve success scholastically. Avci, Yuksel, Soyer, Balikcioglu (2009) agree when they conclude that differentiated teaching has a positive influence and impact on children's learning. For the purpose of this deliberation the concept of differentiated teaching, although it will discussed again later, and the role that Higher Grade (HG) and Standard Grade (SG) options in subject instruction and subject availability can play, should be elucidated at this point.

Tomlinson (2001) says that " a differentiated classroom provides different avenues to acquiring content, to processing or making sense of ideas , and to developing products so that each student can learn effectively."Kruger and Joubert (1997:130) also state that in a well-differentiated educational system , special provision is made by "introducing various types of schools, standards , special schools and classes , subjects of various levels of difficulty , etc.".

In the practical school situation in South Africa, the following adjustments can be made to align practice and theory. SG can differ from HG in terms of the length of the syllabus (shorter for SG), the level of complexity on which the subject is presented (enriched syllabus for $\mathrm{HG}$ ), and a more direct method of assessment (not insight-based questioning) as well as a more lenient approach in the marking process for SG subjects. The value of this approach to influence learning 
positively will become more evident when learning models and curriculum elements are discussed further on in the deliberation.

The career guidance programme that one would like to argue for, should include not only assistance in terms of subject choice, but should also advise on matters concerning admission requirements, bursaries or financial assistance for deserving students and all other aspects related to the preparation of the youth for the world of work. The availability of funding for further studies, guidance concerning career ambitions and personal abilities, values and interests and the value of qualifications and employability are examples of matters that deserve attention. Kartus (2012) points out that there is presently inadequate provision for vocational guidance or assessment of learners in SA and that if appropriate career direction is given in terms of their interest, abilities and personality to point them in the correct direction, it could be to the advantage of the South African economy.

It is obvious that clear and guiding assistance regarding the above mentioned will enable learners to choose and pursue subjects befitting their abilities and with the understanding of the value or need for such subjects for future careers. It can therefore be argued that the teaching and learning process at school should benefit from such a programme and that it will enhance teaching/learning effectiveness in schools. This paper should firstly be seen as an outcry to introduce a system of differentiated teaching which can alleviate stress among learners, resulting from unmanageable academic pressure, and which can improve social adjustment and ensure optimal personal development of learners through academic success. Secondly, the value of career directing information and career directed education as motivational factors or stimuli in the teaching/learning situation should not be underestimated.

\section{Overview of the Problem}

The inclusion or omission of certain subjects in a learner's subject choice and/or failure to provide well-planned and adequate career guidance in secondary schools, can have a limiting effect on a learner's opportunity to develop his/her potential to the full and therefore also will have negative implications for the teaching/learning situation.

Admission requirements for career opportunities or academic programmes at traditional universities or universities of technology are very often subject related. At the University of Technology, Free State (CUT) admission to certain programmes are also determined by the subject combination of the prospective student. The marketing brochure of CUT, Prospectus (2013: 34-50; 62-73) indicates that Mathematics, Physical Science, Life Sciences (Biology) on Standard Grade (SG) or Higher Grade (HG) with a specific pass mark before 2007 and after 2008 a pass mark at a specific percentage are required (either individually or in combination) to be accepted into various programmes of engineering and health technology.

The termination of the HG/SG system and the introduction of Mathematical Literacy as new subject to 'replace' or 'substitute' Mathematics SG, left learners no alternative as to include Mathematical Literacy in their subject choice if they could not cope with original Mathematics due to differentiated potential in the subject. In other subject combinations it was also found that learners, no longer able to go down to SG in a particular subject, included other subjects, not even always aligned with their broad subject choice, to avoid the complex nature of HG subjects. This resulted mostly in the inclusion of 'learning' subjects to substitute the 'more difficult' subjects. Examples of such "difficult" subjects are e.g. Life Sciences, Natural Sciences, and Accounting. This phenomenon should be seen as one of the factors which can lead to the selection of an 'inferior' subject selection which in turn will result in limited career opportunities.

The admission and enrolment of apprentice artisans in various fields was also effected by the inclusion of Mathematical Literacy by learners who struggle with ordinary Mathematics. Mathematical Literacy is not seen as Mathematics and does not equip the potential candidate with the necessary skills and knowledge ideal for the preparation of artisans (Mamorne, 2011).

Concerning the role of Career Guidance, as related matter to what has been discussed in differential teaching, it should be noted that a large number of school-leavers leave school without any form of training beyond school and are to a large extent unemployable in established careers where a career development path can unfold. Another group of matriculants leave school believing that their only chance of future employment is via the university where they can gain some qualification irrespective of their suitability for subjects chosen. Against this background a first year tertiary student drop-out rate of $35 \%$ is not a surprise (Kartus, 2012).

Added to what has been said, Howie (2011) states that the quality of education in South Africa is a stumbling-block in the way of the country's development and also that achievement throughout the system is on an alarming low level. She also said that only a small percentage of learners can be internationally competitive and mentions that serious problems seems to occur concerning the teaching needs of young people and adults. When considering what Whiston (2003), as quoted by Charles Chen (2005), says in this regard, the importance of school guidance and counselling 
programmes becomes even more evident. He pointed out that research has indicated that effective school guidance and counselling in schools facilitate students' development in educational, personal, social and career domains.

In a South African context where numerous problems such as inequality and insufficient workforce capabilities face the workplace, educationists should ask themselves whether we are doing what we should do at school level to alleviate this problem. Are we assisting learners to understand and prepare themselves better for the world of work or just working towards the final examination. Patton (2004) sees career education as performing an integral role in preparing young people for the future. She is of the opinion that school needs to be viewed as learning communities wherein all aspects of their functioning are designed to develop active learners and where connections are made continually between learning in school and in the broader community.

Patton (2005:21-22) also refers to an adopted definition by the Australian Education Council in 1992 where career education in their schools is seen as concerning itself 'with the development of knowledge, skills and attitudes through a planned programme of learning experiences, which will assist students to make informed decisions about school and post-school options and enable effective participation in working life'. Guidance concerning career development should therefore never be seen as an add-on responsibility of someone somewhere along the line of a learner's development which must lead to finding a job, but rather as an integrated, well-designed and planned intervention to give substance, value and meaning to a learner's scholastic development.

\section{Addressing Some More Views on the Matter}

Concerning the responsibilities of teachers Bush and Anderson (2004) mention important education values that need to be instilled, already during the training of teachers, and the following are specifically mentioned:

- the enhancing of the quality experience of learners;

- the promotion of academic excellence;

- the education of learners to the best of their ability;

- the preparation of learners for life after school.

Joubert and Prinsloo (2007:176) refer to the acknowledgement of the uniqueness, individuality and special needs of every learners and the guiding and encouraging of each learner to reach his/her potential as it is embedded also in the Code of Conduct which refers to the relationship between educator and learner. Furthermore, the importance of recognizing the existence of individual differences in the classroom situation should never be ignored. These differences can be identified also in terms of how information is processed, strategies used to solve problems, mechanisms for shortand long term memory and also individual competencies of students and not necessarily so much general abilities and aptitudes (Wang, 1992).

In his discussion of learning models, Mwamwenda (2004) deals with the mastery learning model and the capitalization model. The Mastery learning model implies that individual differences in the learning process can be accounted for by the time factor - meaning that if learners of different learning ability are given time enough based on their pace, it should be possible for them to learn as well as other learners. The capitalization model again, refers to a learners' academic and personal strengths. This means that learners who tend to conform should be provided with structured teaching, while those who are fairly independent and hardworking learners, should be given tasks requiring independent study.

Tuckman \& Monetti (2011:141), in referring to Tomlinson's (2001) identification of curriculum elements that can be differentiated, mention content, process and products as these elements. 'Content' should be aligned with learning goals, it should be focused on concepts and driven by principles. 'Process' refers to the using of flexible grouping and key strategies for classroom and lesson organization and instructional delivery while 'products' refers to continually assessing student readiness and growth, challenging students (learners) to be active and responsible explorers, and varying expectations and requirements for student responses. Furthermore, to be able to differentiate in the classroom, the teacher should, amongst other things, also develop lessons that are engaging and motivating for a diverse class of students - that means vary instructional activities.

Bearing in mind what has been discussed so far and considering that plus minus $68 \%$ of all learners fall in an IQ distribution of 85-115 (Mwamwenda, 2004), the so called normal distribution and finding themselves in mainstream education, one can conclude that the important differences eg. Intelligence, perception, adaptability, background, motivation etc, will also be present in this majority group. Not affording learners the opportunity to choose the best possible subject combination in Grade 9 for the senior secondary phase, will undoubtedly have a negative impact on developing learners to the best of their potential and to assist them in adjusting themselves socially, intellectually and physically as required. The attenuation of a subject choice by choosing alternative subjects with lesser occupational value 
because a learner finds it difficult to manage the more complex, demanding but valuable subject, where a SG version would assist to maintain such a subject, serves the interest of nobody or no system. It only limits occupational possibilities. As example one can mention the substitution of Mathematics by Mathematical Literacy etc.

Regarding the value of Career Guidance to improve the teaching/learning situation in schools, it is necessary to note that provision is made for and time is devoted to career planning in the Life Orientation offered in schools. Questions are however raised whether this is always done scientifically and by appropriately trained professional people.

Life Orientation (LO) aims at educating healthy, responsible young people who will be able to live productive lives in the new South African democracy (Jacobs, 2011). Looking at this noble goal, one is comforted that this educational intervention augers well for the future. Yet, looking at what is experienced in practice, a different picture emerges.

The findings of different writers point out that very little evidence exists to prove that LO achieves the aims as set out in the National Curriculum Statement and that teachers often feel that they have not received the necessary training to present LO effectively (Jacobs, 2011; Prinsloo, 2007; Rooth, 2005; Theron and Danzell, 2006).

In a study by Jacobs (2011) to determine how learners experienced LO, the frequency of addressing learning outcomes showed that Career Choices featured once, compared to Health Promotion/Personal Development, 10 times; Social Development 5 times etc. Jacobs also found that learners, especially those from previous Model-C schools were very negative about LO. Their comments included remarks such as that it was a waste of time, that they had hardly learned anything, that parents can teach one life skills and that it was seen as a "free" or "homework" period.

\section{Methodology}

From findings of other researchers in this field and the researcher's own provisional and informal research and experience, it became clear that not enough is done to prepare learners for life after school while effective school guidance and counseling programmes in schools facilitate students' development in educational, personal, social and career domains. Differentiated and career directed education should therefore be further researched as a possible way to improve the teaching / learning process. Teachers should ask themselves whether they are doing what they should do to improve the overall academic performance in schools.

To verify some of the gathered information from the academic research engaged in, it was decided to use a short, informal questionnaire to determine the practical and scholastic experiences of a group of Education III students regarding subject- and career guidance and information. Out of a group of 70 students, 40 were selected at random to complete the questionnaire anonymously and voluntarily. Their inquisitive and critical participation in class discussions and the fact that, although they have settled down in higher education, they still have contact with senior learners at school, made this group the ideal group for the purpose of this questionnaire.

\section{Results and Discussion}

It should be noted that this analysis has as point of departure from the personal observation and experience of the researcher. Descriptive statistics were used to determine and explain the data distribution and to substantiate the argumentation regarding differentiated and career directed teaching. From a quantitative angle the questionnaire analysis was used and from a qualitative side, the personal reflection of the researcher as mentioned.

It seems that, although career planning should receive attention in the Life Orientation programme, the ineffectiveness in this regard raises many questions. An objective evaluation of this programme and its value should be further researched.

The first alarming fact, referring to the place of career guidance in the Life Orientation Programme, was the fact that teachers felt that their training was insufficient to present LO effectively (Jacobs, 2001; Prinsloo, 2007; Rooth, 2005; Theron and Danzel, 2006).

The fact that Health Promotion/Personal Development and Social Development received far more attention than career guidance and the negative remarks made by learners about LO, is a further concern about the effectivity of the programme.

Interesting information related to this study which became apparentincludes the following:

- At least half (50\%) would have chosen a different career if they had a subject choice enabling them to do so. From discussion later, it was clear that the limiting effect of HG and SG subject opportunities was one of the reasons for this outcome. As indicated before, the inclusion of subjects of "lesser value ", e.g. Mathematical Literacy instead of Mathematics SG is an example. 
- $60 \%$ would have chosen a better subject combination if they have received better/more information regarding admission requirements and subject values. In this regard, the admission requirements for further studies in term of compulsory subjects need to be mentioned.

- Only 10\% felt that they received adequate subject information to make an informed choice in Gr 9.

- Only 15\% felt that they received adequate information about specific admission requirements for different fields of study or careers.

- $\quad 75 \%$ of the group indicated that subject- and career guidance should receive more attention at secondary school level.

The above-mentioned findings and remarks serve as a clear indication that the attention given to Career Guidance as subject component in schools is lacking to prepare learners to pursue careers that could benefit them more or fit them better. This unfortunate situation also contributes to the inability of the schooling system to provide both the labor market and training institutions with well-prepared and equipped clients and can also negatively impact on the economic wellbeing of the country.

The results obtained from the questionnaire completed by the Education III group and the lively discussion that followed when the outcomes were discussed was convincing proof that there are reasons for concern.

When considering all the findings, comments, results and practical circumstances that have been dealt with so far, it is evident that the existing situation in South African schools in so far as dealing with career- and subject guidance, is far from ideal and does not contribute positively towards a favorable teaching and learning situation in South African schools.

\section{Conclusion and Recommendations}

All the years spent at school cannot and should not conclude in a goal of merely obtaining a school leaving or equivalent certificate. It became clear that a system without the option to take or study a subject on differentiated levels, HG and SG, will limit developmental options and opportunities. At universities of technology, learners with a Mathematics SG qualification may still access courses in engineering and/or certain health sciences programmes, but these programmes will not be accessible with Mathematical Literacy. This also applies to the training of artisans in different fields and the ideal situation should be a system where "through formal and non-formal education, the school has a special task in satisfying the RSA's differentiated manpower needs as has been the case in many other countries such as Israel, Taiwan, Japan, Thailand etc. (Jacobs, Van Jaarsveld and Von Mollendorf, 1991:75).

Concerning tuition and assessment the system of differentiated teaching can also alleviate stress among learners, resulting from pressure where a subject in its original complex form cannot be managed, and it can furthermore also improve social adjustment and ensure optimal personal development in a normal school situation. It is also reasonable to expect that an improved pass rate in subjects will follow as a result of an adjusted and differentiated curriculum and assessment criteria as discussed earlier.

In fulfilling its educational task of teaching and learning, the school does not only prepare the child for the world of work, but at the same time the career directed character of the process to develop knowledge, skills and attitudes, also gives direction and meaning to the learning process or experience.

The absence of Guidance as a subject, or even a service in the school, and the inability of teachers due to lack of training, enthusiasm, dedication or what other reason to give appropriate guidance to learners in terms of their career planning, are neither to the advantage of the learners nor the teaching profession and the world of work. Possible guidelines to combat existing problems concerning differentiation and career guidance that have been indicated and discussed, should be considered because it is believed that adequate, properly planned and creatively constructed strategies to improve subject- and career guidance will not only improve the existing situation, but it could also lead to the opening up of debate amongst educators to re-introduce a system of differentiated subject instruction and a proper career guidance programme that will benefit learners and the process of teaching and learning.

Firstly, the re-introduction of HG and SG subject levels in teaching, curriculum construction and assessment is recommended for the senior secondary school and it should be debated seeking the input of various stakeholders such as commerce and industry, institutions of higher learning, institutions for further education and training, non-governmental organizations, parent bodies and educators.

The following recommendations could be considered as guidelines to counter existing problems until a better system can be established in schools.

- Involvement of parents to inform learners about their personal careers and professions.

- Involving trained people in LO programmes while allowing more time for career guidance. 
- $\quad$ Using the services of recruitment and/or academic staff from universities, FET Colleges and representatives from industry to give information regarding artisans in various fields.

- Subject teachers should explain the career value of their subjects.

- Services of NGO's such as Pulse, EVA Solutions, Perfect Careers, PACE and others should be utilized in career guidance through existing programmes. Their assistance through internet information, work books, programmes such as Career Mapper etc. and the involvement of sponsoring companies can be of invaluable assistance (Kartus, 2012:2-3) to distribute information and assist in psychometric evaluation.

The success of the mentioned recommendations will largely depend on the appointment of an interested, willing and able staff member to act as coordinator to structure and execute all actions between the school and external participants.

To conclude - the value and importance of befitting, enabling and well-planned subject choices on an acceptable instructional level must never be underestimated. It will pave the way for learners to develop according to their potential and improve teaching/learning in the classroom due to alleviated stress and the motivating force of success in a manageable academic programme. Equally important to ensure equilibrium in the teaching/learning process and the life of the learner, is the career preparation of each learner to emphasize that the ultimate goal of twelve years of schooling lies beyond the certificate at the end of Grade 12.

The importance of correct subject combinations, self-knowledge, the availability of a wide variety of careers, practical, academic or professional, and the demands and requirements of these careers will assist learners to choose wisely for the future.

It is my firm belief that the teaching/learning effectiveness in schools will benefit from the introduction of a wellplanned system of differentiated and career directed education. The ultimate goal of teaching cannot be a school leaving or equivalent certificate. Schooling should serve as preparation for life after school and for a future career. The role that differentiated and career directed teaching can play to give direction and add value to the teaching / learning process in schools can eventually lead to a more effective academic process and deserves further and deeper discussion and research in the South African context. The fact that the only quantitative research done was the questionnaire analysis, may be seen as a limitation. The absence of a control group and/or co-researcher to triangulate information is a further limitation that should be taken note of. If, however, debate can be reopened on the matter of differentiated and career directed education in the South African education landscape, the purpose of this contribution would be well-served.

\section{References}

Bush,T. \& Anderson, L. (2003). Organisational culture. In Coetzee, S.A. \& Van Niekerk, E.J. \& Wydeman, J.L. An Educators Guide to Effective Classroom Management. Revised Third Edition 2010.

Chen, P.C. (2005). Counsellor and Teaching Collaboration in Classroom based Career Guidance. Journal of Career Development, Volume 14, Nr.3, Spring 2005.

EVA Solutions, http://www.evasolutions.co.za/Our Services/Career Guidance/ GuidanceinSchools.aspx . Career Guidance in Schools. Downloaded/Retrieved 28-08-2012.

Howie, Sarah. (2011). Kenner waarsku oor swak Onderwys in SA. Volksblad, 8 Augustus 2011. (South African Newspaper).

Jacobs, H. (2011). Life Orientation as experienced by learners: a qualitative study in the North-West Province. South African Journal of Education, Volume 31.

Jacobs, C.D. \& Van Jaarsveld, N.H. \& Van Mollendorf, J.W. (1991). Career Guidance for the Primary and High School, Unibook Publishers Pty. Ltd.

Joubert, R. \& Prinsloo, S. (2007). The Law of Education in South Africa (Second Edition). Van Schaik Publishers, Pretoria.

Kartus, L. The Importance of Career Guidance \& its Impact On South African Business. http://www.workinfo.com/free/downloads/ 276.htm?Back.x=12\&Back.y=15 Downloaded/Retrieved 28/08/2012.

Kruger,A.G. \& Van Schalkwyk, O.J, (1997). Classroom Management. J.L. van Schaik Publishers. (Second Edition.)

Mamome, M.S. (2011). Discussion on admission requirements for training artisans. Lecturer, Motheo FET College, Hillside View Campus, Bloemfontein, RSA.

Mhlanga, P. The Significance of Career Guidance for High School Learners. http://www.ngopulse,org/print/17637. Download/Retrieved $11 / 09 / 2012$

Mwamwenda, T.S. (2004). Educational Psychology, An African Perspective. (Third Edition). Heinemann Publishers.

Patten, W (2005). A postmodern approach to career education: What does it look like? Perspectives in Education, Volume 23(2), June 2005.

Patten, W. (2004). Career Guidance and public policy: bridging the gap. Organization for Economic Cooperation and Development 2004.

Prinsloo, E. (2007). Implementation of Life Orientation programmes in the new Curriculum in South African Schools: Perception of Principals and Life Orientation Teachers. South African Journal of Education. 27.

Prospectus. (2013). Annual Marketing Brochure of the Central University of Technology, Free State in Bloemfontein, RSA. 
Rooth, E. (2005). An investigation of the status and practice of Life Orientation in South African Schools in two provinces. Ph.D theses. Cape Town: University of the Western Cape.

Avci, S., YÜksel, A., Soyer, M., \& Balikcioglu, S. (2009). The Cognitive and Affective Changes Caused by the Differentiated Classroom Environment Designed for the subject of Poetry. Education Sciences: Theory and Practice V9 n3 p1069-1084 Sum 2009. (EJ 858920).

Theron,L.C. \& Danzell, C. (2006). The specific life orientation needs of Gr 9 learners in the Vaal Triangle region. South African Journal of Education, 26.

Tuckman, B.W. \& Monetti, D.M. (2011). Educational Psychology. Wadsworth, Cengage Learning.

Wang, M.C. (1992). Adaptive Education Strategies - Building on Diversity. London: P.H.Brooks Publishing Company.

Whiston, S.C. (2003). Outcomes research on school counseling services. In B.T. Erford, (Ed), Transforming the School Counselling profession (pp436-47). Upper Saddle River; NJ: Merrill Prentice Hall/Pearson Education Inc. 